\title{
Optimization of combined production of electricity and hydrogen at nuclear power plants using a neural network
}

\author{
Ilia Lopyrev ${ }^{1}$, Vadim Golubev $^{1}$, Daria Voznesenskaya ${ }^{1}$, Victoria Verbnikova ${ }^{1}$ and Olga \\ Novikova $^{2 *}$ \\ ${ }^{1}$ Peter the Great St.Petersburg Polytechnic University, 195251 St. Petersburg, Russia \\ ${ }^{2}$ National Technology Initiative Center for Advanced Manufacturing Technologies based \\ on the Institute of Advanced Manufacturing Technologies of Peter the Great St. Petersburg \\ Polytechnic University Polytechnicheskaya, 29, St.Petersburg, 195251, Russia
}

\begin{abstract}
This article discusses a project with a basis on implementation of combined production of electricity and hydrogen based on a HTGR reactor in the Primorsky Krai of Russia. One of the major advantages of the fourth-generation reactors of the HTGR type is, that water vapor reaches 800 degrees Celsius, which allows not only to efficiently transfer thermal energy to external circuits, but also to use it in the production of hydrogen using the steam reforming of methane [1]. The results of the research were composed mainly of two fully-calculated investment projects, which showed an significant increase in the economic efficiency of combined production of electricity and hydrogen when included in the neural network planning system. Moreover, further technological advancement in developing this method of forecasting could prove highly beneficial in implementing a higher percentage of renewable energy sourced power plants into energy industry[2].
\end{abstract}

Keywords: hydrogen, atomic power plant, artificial neural network, sustainable development, energy engineering

\section{Introduction}

The power industry of the Far East today is characterized by outdated generating capacities, as well as instability of the load distribution. The current state of affairs in the energy sector does not allow the region's enterprises to achieve sustainability. An alternative power supply option can be the construction of a nuclear power plant, but the peculiarities of the regulation of the load of nuclear power plants require optimization of production modes, an increase in the energy efficiency of processes and a more accurate forecast of energy demand.

\footnotetext{
*Corresponding author: novikova-olga1970@yandex.ru
} 
The main purpose of the article: to study the efficiency of using neural networks in the implementation of combined production of electricity and hydrogen at a nuclear power plant in the Primorsky region.

The object of the research is the combined production of electricity and hydrogen in the Primorsky Territory of Russia. The subject of the research is the effect of using neural networks to optimize the operating mode of a nuclear power plant with combined generation of electricity and hydrogen.

Atomic-hydrogen energy is aimed at expanding the methods and volumes of consumption of nuclear energy in energy-intensive sectors of the chemical, metallurgical, construction, fuel industries, as well as in transport[3].

\section{$2 \quad$ Materials and methods}

Currently, open sources of information are filled with information on the technologies of combined production of electricity and hydrogen, using nuclear power plants, but one of the few the close to producing a prototype is the use of the GTHTR300 reactor and the HTGR reactor in the steam conversion of methane. For research purposes in the article, a project with an HTGR reactor was selected[4].

Nuclear plants, which can reduce their power output to the power system, but maintain an overall stable load for hydrogen production, can change the principles of control planning, which will then require the use of additional optimization tools, which are able to import the distribution of the thermal power of a nuclear power plant among several types of products into the calculation process[5]. We highly recommend using self-learning neural networks for optimization purposes, which have a number of important advantages:

1. Flexibility - since the operator determines only the major parameters of the network, and the weights of each bond are calculated automatically and constantly adjusted to increase the final accuracy rating[6].

2. Speed - neural networks make full use of the capabilities of computing devices, since they work mainly using CUDA, which allows them to work faster than specialized software[7].

3. Ability to learn on a constantly growing sample of data.

4. Higher forecasting accuracy compared to established methods[8].

Thanks to all of the above features, neural networks allow, on the basis of statistical data and complex mathematical models, taking into account each significant factor, to predict daily load graphs with high accuracy, predicting even sharp jumps in values [9].

In contrast to the standard methods of predicting the load schedule for electricity and hydrogen production at nuclear power plants, it is expected to use optimization algorithms for medium and short-term planning of electricity and hydrogen output based on the data generated by the neural network. The optimization algorithm includes many factors, such as[10]:

1) air temperature;

2) hourly load on the regional power system;

3) additional operating costs associated with a change in the operating mode of the power plant;

4) supply and demand for finished products;

5) other limiting factors, for example, the maximum capacity of the complex for the production of electricity, hydrogen, its liquefaction and transportation. 


\section{$3 \quad$ Results and discussion}

For a neural network of 4 layers (a layer of input parameters, 2 hidden layers and a layer with a result), the function value is determined by the formula:

$$
S_{l}=\sum_{k=0}^{n 2}\left(g_{l k}\left(\sum_{j=0}^{n 1}\left(f_{k j}\left(\sum_{i=0}^{n}\left(x_{i j} * w_{i j}\right)\right) * w_{k j}\right)\right) * w_{l k}\right)
$$

where

$S_{l}$ - output value

$f_{k j}$ - function of activation of neurons of the 1 st hidden layer

$g_{l k}$ - function of activation of neurons of the 2nd hidden layer

$\mathrm{n}, \mathrm{n} 1, \mathrm{n} 2$ - the number of neurons in the input, 1 st hidden and 2 nd hidden layers, respectively

$w_{i j}$ - connection weights of neuron $\mathrm{i}$ of the current layer and neuron $\mathrm{j}$ of the next layer

To build a predictive model, a feedforward neural network of a perceptron type was used, which made it possible to significantly simplify the structure of the calculations, reduce the required time for forecasting and training, and also make the model more universal due to the simplicity of the network type[11]. The resulting accuracy rating is $99,6 \%$.

Combined production of electricity and hydrogen imposes additional restrictions on the operation of the hydrogen production complex and the power plant, which require correct calculations of the most effective volume of hydrogen, adjusted for climatic and other factors indicated above, as well as the requirements of the electricity market. And, as mentioned before, neural networks are ideal for solving such problems online[12].

The construction of a complex for the combined production of electricity and hydrogen, its liquefaction and transportation is a long-term multithreaded process that requires efficient planning. For its implementation, at the initial design stage, a roadmap is created that shows the main milestones and processes with an indication of their projected timing. In the case of the project considered in this paper, the list of planned activities is presented in Figure 1.

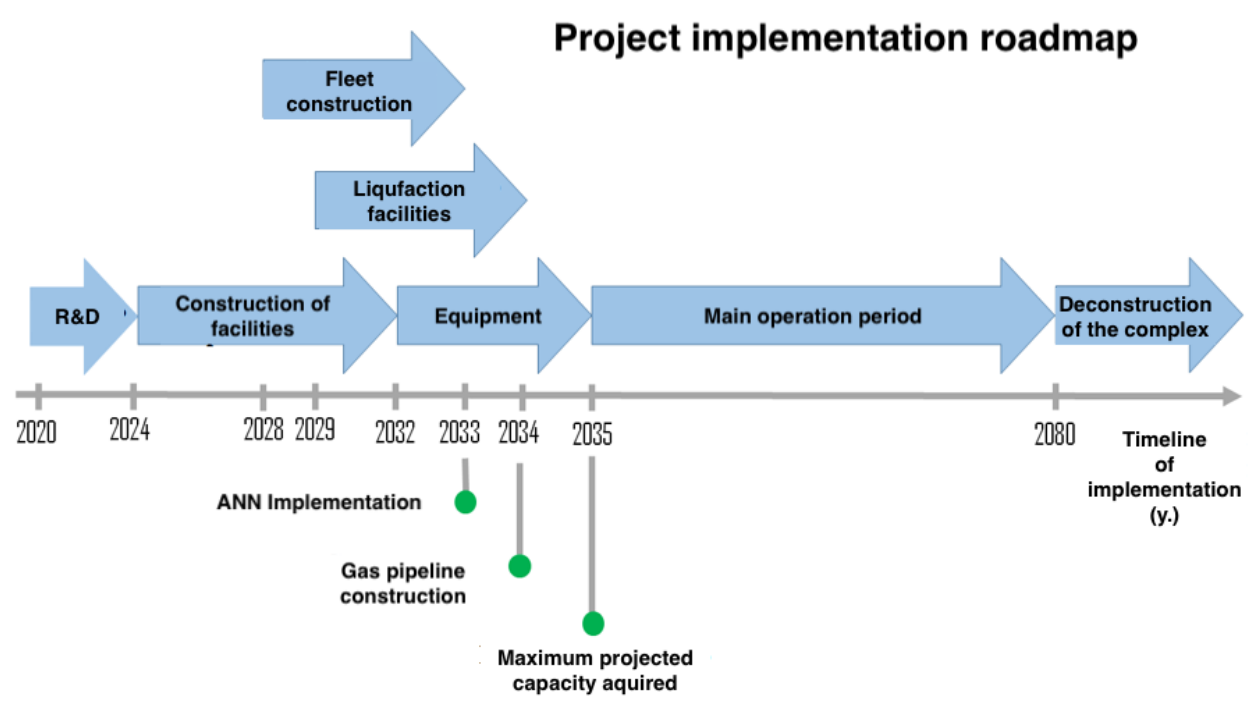

Figure 1. Project implementation roadmap 
For a feasibility study for the implementation of neural network optimization in the combined production of hydrogen and electricity, two investment projects were calculated for the construction of a nuclear power plant from two units with a HTGR-300 reactor, a hydrogen production workshop, a gas liquefaction station with the purchase of several ships for transportation, taking into account the costs of construction of a gas pipeline to ensure the process of steam conversion of methane and logistics costs for the supply of finished products to consumers within the region. Overall, capital expenses structure is represented in Graph 1.

\section{Capital expenses distribution}
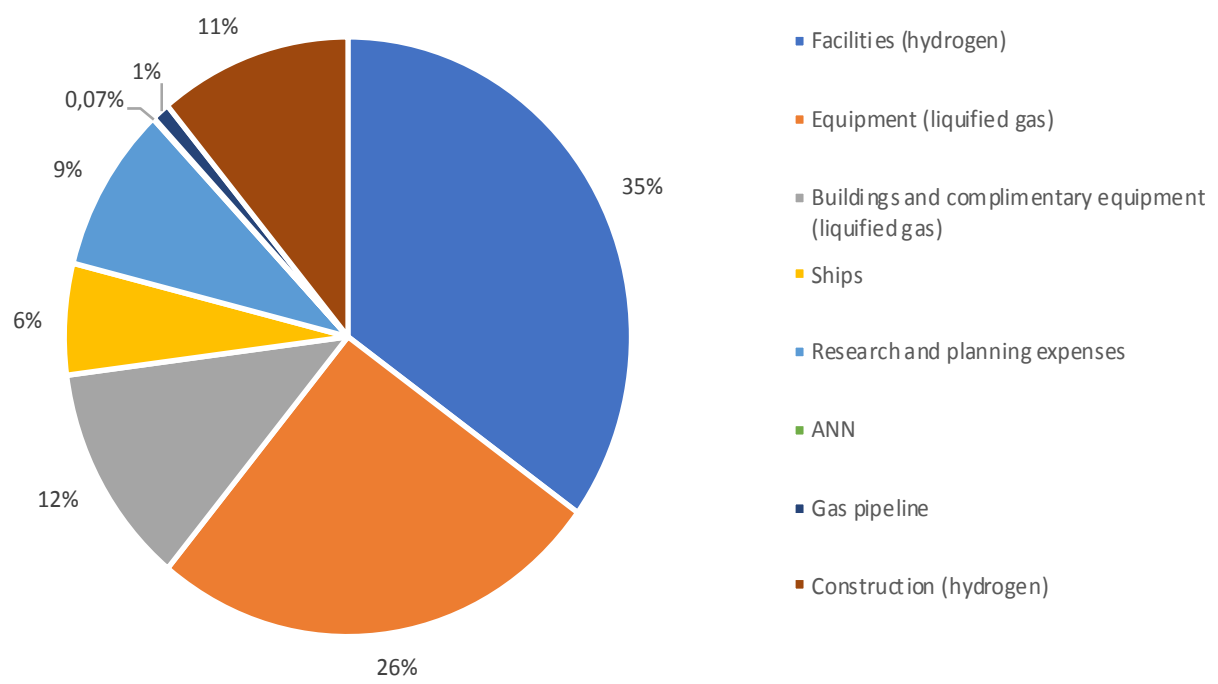

Graph 1. Capital expenses distribution

The costs of the artificial neural network and the infrastructure corresponding to it will amount to only about 100 million rubles, which were considered for the creation of the network itself and the server infrastructure[13].

Table 1 presents a comparative assessment of two projects: with an optimization model based on a neural network and without it.

Table 1 - Comparison of the main economic indicators of project efficiency

\begin{tabular}{|c|c|c|}
\hline ANN & Included & Excluded \\
\hline Discount rate, $\%$ & \multicolumn{2}{|c|}{$10 \%$} \\
\hline IRR, $\%$ & $12,13 \%$ & $10,57 \%$ \\
\hline MIRR, $\%$ & $11,43 \%$ & $8,91 \%$ \\
\hline NPV (mln.RUB) & 15609,02 & 3984,48 \\
\hline PI & 1,38 & 1,03 \\
\hline DPBP, years & 33 & 46 \\
\hline
\end{tabular}

The internal rate of return increased by $1.56 \%$ after the implementation of the optimization model, which indicates an undeniably positive impact of the neural network on the economic efficiency of the project.

With all other factors being equal, the option with an embedded neural network pays off in 18 years of operation, and a project without an optimization model does not pay off under 
these conditions, which only confirms the conclusion about its low investment attractiveness in a conservative implementation scenario.

\section{Conclusion}

The expansion of hydrogen production in Russia today is one of the research areas for achieving sustainable economic and energy development[14]. The complex considered in the article with the possibility of combined generation of electricity and hydrogen will make it possible to replace some of the outdated capacities, normalize electricity prices and cover load peaks[15]. The neural network not only gives us the tools for accurate and, potentially, long-term forecasting of electricity demand, but also allows us to more efficiently use all the required types of fuel, increase the profitability of the complex and optimize the equipment load mode[16]. In addition, long term sustainable development plans suggest, that neural networks may become a key to unlocking the full potential of renewable energy sources, compensating their instability with extremely accurate forecasting.

\section{References}

1. Grebennik V.N., Kukharkin N.E., Ponomarev-Stepnoy N.N. High-temperature gascooled reactors are an innovative direction in the development of nuclear power. - M.: Energoatomizdat, 2008.- 136 p.: ill. - (Physical and technical problems of nuclear power).

2. Radchenko, R.V. Hydrogen in power engineering: [Text] textbook / R. V. Radchenko, A. S. Mokrushin, V. V. Tyulpa. - Yekaterinburg: Ural Publishing House. University, 2014.- 229 p.

3. Association of independent experts in the field of mineral resources, metallurgy and chemical industry "InfoMine": Overview of the market for hydrogen and equipment for its production in Russia (3rd edition). - M.: OOO IG InfoMine. 2018.-- 138 p.

4. Egorov, M., Kalyutik, A.A., Akhmetova, I.G., Makoev, S.O. Heat transfer in coiled type superheater of moisture separator reheater of turbines at the nuclear power plant// IOP Conference Series: Earth and Environmental Science. 2019

5. Loginova Svetlana Sergeevna, Kukhnina Olga Andreevna, Sumenkova Tatiana Vyacheslavovna, Duntsev Andrey Vsevolodovich High-temperature gas-cooled reactors // Bulletin of Science and Education. 2018.

6. N.N. Ponomarev-Stepnoy et al. Nuclear power engineering complex with hightemperature gas-cooled reactors for large-scale environmentally friendly production of hydrogen from water and natural gas. / Gas industry, No. $11-2018$

7. Faustova K.I. Neural networks: application today and development prospects // Territory of science. 2017.

8. Jianchang Mao, Enil Jane Introduction to artificial neural networks / Jianchang Mao, Enil Jane // Open systems. DBMS. - 1997. - No. 4.

9. Chapter 3. Fundamentals of ANN, [Electronic resource] - URL: http: //neuralnet.info/chapter/\%D0\%BE\%D1\%81\%D0\%BD\%D0\%BE\%D0\%B2\%D1\%8B$\%$ D0\% B8\% D0\% BD\% D1\% 81 / (date of circulation 01/18/2020)

10. Ponomarev VS, Finaev VI Application of adaptive regulators based on neural networks in power engineering // Izvestiya SFedU. Technical science. 2008.

11. Anikeev Maxim Vladimirovich, Babenko Lyudmila Klimentievna, Makarevich Oleg Borisovich Review of modern types of neural networks // Radioelectronics, informatics, management. 2001. 
12. Maryam Imani, Hassan Ghassemian, "Sequence to Image Transform Based Convolutional Neural Network for Load Forecasting", Electrical Engineering (ICEE) 2019 27th Iranian Conference on, pp. 1362-1366, 2019.

13. Widrow, Bernard, et al. "Neural networks: applications in industry, business and science." Communications of the ACM, vol. 37, no. 3, Mar. 1994, p. 93+. Gale Academic OneFile, . Accessed 27 Nov. 2020.

14. Savchenko NA Neural network technologies in the optimization of power systems // Izvestiya TulGU. Technical science. 2011.

15. Yang Lin, Irena Koprinska, Mashud Rana, "Temporal Convolutional Neural Networks for Solar Power Forecasting", Neural Networks (IJCNN) 2020 International Joint Conference on, pp. 1-8, 2020.

16. Atomic expert // Hydrogen is a new key product of Rosatom - 2019 - [Electronic resource] - URL: http://atomicexpert.com/hydrogen_project_rosatom (date of access: 21.11.2020) 